\title{
Conclusion: passion and politics
}

This book is political. Not because it started with an explicit commitment to a particular political project but because it did not. Not because the author took the position of 'activist-scholar', but because the 'ugly' politics of the movement studied rendered such a role inappropriate. But must research on activism always take the form also of political action? If so, do we not exclude the possibility of close-up research of those political causes and movements that we find, personally, most difficult to comprehend and, socially, most pernicious? And does not such self-imposed constraint on what and how we research not weaken claims to the systematic creation and critique of knowledge (Gillan and Pickerill, 2012: 136)? This is not to dismiss the political implications of choosing to conduct an ethnographic study of a movement widely perceived to actively perpetuate racism. It is to take the position that there should be no areas of social life that are unfit for scientific study (Kirby and Corzine, 1981: 15) and to argue that such studies extend our, very limited, understanding of the meanings individuals in movements of the populist radical right attach to their activism. It is also to suggest that such studies have political as well as academic value.

\section{Ethnography: a choice between politics and knowledge?}

Traditional studies of the far right tend to forefront the analysis of ideological frames and organisational effectiveness and take little account of the people who maintain such movements; individuals appear largely in the form of agglomerated socio-demographics of 'supporters' or 'voters' or as an undifferentiated mass following a charismatic leader. Ethnography, in contrast, allows the researcher to approach and present members of such organisations 'as individuals with real lives' (Ezekiel, 1995: xxxv). This is not to underestimate the contentiousness of what that implies; understanding the meanings attached to activism requires a sustained presence in activists' lives. When the individuals concerned are active in 'distasteful' groups, this is both difficult and controversial. But, it is argued here, it is necessary. 
It would be simpler - and pointless - to simply reinforce the reader's stereotypes and pander to the reader's pre-existing images. It takes no effort to speak glibly about a stereotype. ... To present white racists as humans is not to approve their ideas or their actions. But to picture them only in stereotype is to foolishly deny ourselves knowledge. Effective action to combat racism requires honest enquiry. (1995: xxxv)

Over the course of conducting and writing this research, I came to understand this as a political as well as an academic stance. Of course Kalra (2006: $466)$ is right to argue for the importance of research that goes beyond 'acknowledging the role of racism in racialized minorities' lives'. But I take issue with his suggestion that ethnography is always an inappropriate method for challenging racialisation because it is compelled 'towards the dead-end of cultural difference' (2006: 459). Ethnography can, and does, explore the nuances, slippages and conscious and unconscious transgressions of cultural boundaries (ascribed, appropriated or resisted); indeed this is its value. Ethnography is 'an indispensable tool, first to pierce the screen of discourses ... which lock inquiry within the biased perimeter of the pre-constructed object' (Wacquant, 2008: 9). It is also an appropriate tool for researching 'distasteful' groups if ethnography is understood as unpicking rather than enacting moral simplifications - as more than a question of 'whose side are we on?' (Duneier and Back, 2006: 553). It is this understanding of ethnography that is adopted in this study. It is an approach which prioritises not 'documenting the ways in which capitalist pigs exploit subalterns, but being able to see the ways that different kinds of victims confront one another' (2006: 553). As Duneier and Back indicate, referring to interactions between black, homeless street vendors and white middle-class women, it is these moments that challenge our understandings of the world and extend our knowledge of it:

... what I was seeing on the street was a group of liberal white women who are victims of these black men as women. They were wealthier, but the poor black men were able to subvert their race and class position by using their position as men to undermine these women with their taunts and with the things that they say to them and the way that they would undermine conversations with them, and they would apparently feel power at those moments. So those women were victims. It was one group of victims confronting another in public space. (Duneier and Back, 2006: 553)

While I would not choose to designate those who are the focus of the current study as 'victims', their actions in public spaces have contexts that require analysis and interpretation rather than a priori moral condemnation. In seeking to make sense of activism in movements like the EDL, the potential of ethnography to get at the humanity of people (Duneier and Back, 2006: 554) is a powerful tool for revealing the intersections of oppression and thus also the potential sites of cross-cutting solidarities. The exclusion of such groups from such scrutiny in the interests of the researcher's own political or ethical comfort thus denies us important knowledge 
and constitutes not the enactment of an active political stance but, on the contrary, a form of political 'faintheartedness' (Laclau, 2005: 249).

\section{Understanding the EDL: representation, self-ascription and critical interpretation}

This book is about the meanings individuals attach to activism rather than about the EDL as an organisation. If we start from the assumption that action is meaning-making, then it follows that a variety of meanings are made by activists in any movement (Beck, 2015: 93). Indeed, one of the findings of this study has been the diversity of people, positions and meanings attached to activism within the EDL. However, given the political sensitivity surrounding the EDL, its characterisation as an organisation cannot be evaded. The default position for an interpretivist social scientist would be to describe the movement as it is understood by the individual activists studied. In the case of research with 'distasteful groups', however, we are compelled to subject this understanding to the critical perspective of the outsider. Treading a fine line between the conflicting demands of capturing the meaning of the movement for its supporters and employing critical judgement of the movement arising from observation, the EDL has been characterised here as an anti-Islamist movement. This is in tune with other academic studies that conclude that the EDL is distinct from the 'archetypal far-right party' (Copsey, 2010: 25) and operates as a social movement (Copsey, 2010; Jackson, 2011a). Describing it as 'anti-Islamist' reflects the single-issue focus - protesting against 'militant Islam' - of the movement as well as its defensive (politics of fear) rather than visionary (politics of hope) stance. At the same time it is recognised that there is slippage at movement level, and among individual supporters, into a broader anti-Islam or anti-Muslim position.

As an organisation, the EDL makes for a slippery object of study. This, it has been argued here, is not only because of the diversity within its ranks but because the movement is constituted in reflexive engagement with its own external representation. This representation as racist (as well as thuggish, drunken and uneducated) is a constant concern of activists. At one level these media representations of the movement confirm a sense of victim status and 'conspiracy' between political and cultural elites to silence 'ordinary' voices and concerns; in this sense they serve a bonding function. At the same time, exclusively negative portrayal of the movement is demotivating and undermines individuals' sense of efficacy. It is also materially damaging; the failure to rid the movement of its racist image is ostensibly the reason for the resignation of its founding leaders.

In contrast to the victim relationship the EDL perceives itself to have in relation to traditional media, it has used digital media - especially Facebook - extensively to organise, network and disseminate. However, the relationship between the EDL and the media, new and old, is more complex than suggested in existing literature. While social media have been employed relatively effectively to circumvent 'media blackout' in the traditional mass media, it remains a site of tension. Although significant control over Facebook use is devolved to local 
divisions, the right to 'say it as it is' emerges as a source of conflict between older and younger supporters and between 'admins' and grassroots activists. Many individual activists are sceptical and often hostile to the medium, prioritising faceto-face interactions that are better able to evoke the trust and loyalty central to the meanings individuals attach to their activism. Thus, the traditional media remain symbolically and politically important to the movement as it juggles the desire to get its message heard and its experience of engagement as one in which 'the only attention is bad attention'.

\section{Real lives}

Approaching this study as one that looks beyond organisational ideology to the individuals, with real lives, that constitute the movement, respondents are introduced as rounded individuals whose diverse trajectories in and out of activism are embedded in personal life stories. Activists, it is argued, are neither born, nor aggressively recruited, into the EDL. They are neither duped by a charismatic leader nor are they working-class anti-heroes. Their trajectories in and out of the movement are prosaic rather than heroic. Moreover, in contrast to the decisive entrances and exits into and from classic far right movements, activism in the EDL resembles rather a 'hokey-cokey' in which activists repeatedly engage and 'step-back' as they marry the costs and consequences of participation with their wider lives.

In tracing individual trajectories into extreme right activism, Linden and Klandermans (2007) elucidate a number of 'types' ('revolutionaries', 'wanderers', 'converts' and 'compliants'). While these are useful for distinguishing between experiences of activists, evidence from this study suggests that at both organisational and individual level, elements of more than one type are usually combined. Many activists participating in this research, for example, might be classified as 'converts' (2007: 184) in as much as they narrate their decision to join the EDL in terms of their experience of, or resistance to, injustice. However, post-hoc narrations cannot be equated with motivations for participation, and the emphasis on a life-changing moment in charting paths into the movement is not an accurate reflection of the longer and more multi-factorial process of joining the EDL encountered in this study. Thus, it is concluded, there is not one 'type' of person that is attracted to a movement like the EDL; rather decisions to start, continue and draw back from activism are set within a complex web of local environment, familial socialisation and personal psychodynamics.

For the ethical and methodological reasons discussed in the Introduction, full justice cannot be done in this book to the structural factors - especially environmental factors related to changes in local communities - that help explain paths into activism. However, the structural locations individuals inhabit are explored through respondents' perceptions and narrations of them. Traumatic and abusive experiences in childhood, as well as the experience of being bullied, are identified as persistent themes of personal and family psychodynamics. Political socialisation into the extreme right within the family is identified in some cases but is 
absent in others while friends and acquaintances rarely 'recruit' participants into the movement. Activism, rather, appears to be a site of the formation of new affective bonds of 'family', 'friendship', 'loyalty'.

\section{Ideological dimensions of activism}

The EDL claims to be a single-issue movement protesting against 'radical Islam' and disrespect for British troops. While, as noted above, academic studies tend to confirm the movement's own claims to being 'different' from traditional far right parties, they are sceptical about its insistence that it is 'not racist' and interpret it as 'clearly Islamophobic' (Allen, 2011: 203). This study, focusing as it does on the self-understandings and behaviour of grassroots activists concludes that individual activists (mainly) demonstrate a genuine aspiration to non-racism. At the organisational level, respondents concede that historic links with the BNP and the National Front mean that racist elements are encountered within the movement but remain adamant that this does not mean the movement itself is racist. They point to the commitment to 'kicking out racists' and to making the movement 'open to all' (regardless of colour, ethnicity, faith, gender and sexuality) as evidence of this aspiration. Central to respondents' understanding of the movement's non-racism is its hostility towards traditional far right parties (especially the BNP).

At the individual level, activists construct a non-racist self by mobilising a narrow definition of racism as prejudice based on skin colour. Their own nonracism is then confirmed on the grounds of their lack of such prejudice towards, and personal relationships with, non-white people. This 'non-racist' subject position is sealed by excluding any acknowledged discomfort with Muslims as not a question of 'race' because being 'Muslim' is not a racial but religious identifier. This allows individuals to hold, or condone others', anti-Muslim and anti-Islam sentiments since Muslims are consciously excluded from constituting a racially defined group and thus being a possible object of racism.

Thus central to the non-racism claimed by EDL activists is the appeal to a simple, and narrow, definition of 'race' and racism rooted not in a consistently post-racialist politics but akin to the 'post-race' argument, which does not deny the 'reality' of race but argues that it should not be grounds for prejudice and discrimination. This, of course, leaves the movement and its participants open to the accusation that they underestimate the continued impacts of racisms. This is evident in the presence of a range of 'everyday' racisms in EDL milieux and respondents' almost universal failure to recognise the structural conditions underpinning racism.

In sharp contrast to the importance attached to distancing themselves from racism as they understand it, EDL activists openly articulate the belief that there is a 'problem' with Islam that is not associated with other aspects of multicultural society. The findings of this study demonstrate that Islam is understood by EDL activists as 'separate and other' in a way determined by the Runnymede Trust (1997) to be characteristic of an Islamophobic mindset. While amongst activists there are those who explicitly distinguish only 'radical', 'extremist' or 'militant' 
Islam as the object of their concern, there is also routine slippage into talk of Islam or Muslims as single entities and a failure to distinguish between different branches of Islam, different ethnic groups among Muslims or between 'extremist' and 'moderate' readings of Islam.

Central to respondents' claims that the EDL is 'not racist' is that hostility is expressed towards 'Islam' rather than 'Muslims' or ethnic groups of Muslim faith. For this reason, data on associations with Islam and associations with Muslims were analysed separately in this study. This revealed that respondents frequently emphasised that their hostility was towards Islam rather than Muslims and that generalised anti-Muslim sentiments were often replaced by criticisms of what respondents understood to be Islamic doctrine or teachings. Moreover, in contrast to the most frequent associations of Islam with extremism, terrorism and violence found among the UK general population (Field, 2012: 150), the primary tropes in associations with Islam among EDL activists in this study are that Islam is 'backward-looking', oppressive and intolerant (as well as aggressive and supportive of terrorism). This is encapsulated in the understanding of Islam as an 'ideology' rather than a religion and of the EDL as an organisation as anti-Islamist rather than Islamophobic.

Being anti-Islam, however, does not exclude being anti-Muslim also. Evidence from this study shows slippage, especially in the context of songs and chants at demonstrations, into the use of generalised terms of abuse towards Muslims. The question of whether this hostility is directed at Muslims as members of particular ethnic groups or 'immigrants' rather than against Muslims as a religious group as suggested by Halliday's (1999) preference for the term 'anti-Muslimism' over Islamophobia - is more complex. Explicit racialisation, in the form of abusive rhetoric, is identified among a number of respondents alongside the equally explicit rejection of any such racialisation and abuse among others. Similarly, the association of Muslims with violence and terror by some is accompanied by a rhetoric of differentiation between 'extreme' and 'moderate' Muslims by others.

When talking about 'Muslims' (as opposed to 'Islam'), it is important to note, associations with ideologically motivated terror are less common than reference to localised, everyday 'intimidating' behaviour, threats or violent actions perpetrated by 'Muslims'. This suggests that alongside a non-racialised anti-Islamist ideological agenda runs an anti-Muslim sentiment that is expressed through more everyday encounters and community relations and in which Muslims are perceived as particularly problematic and unwelcome immigrants. Islam is a contributing but not exclusive factor in this. Thus, this study suggests that Bleich (2011: 1587 ) is right to argue for a definition of Islamophobia that recognises its multidimensionality and includes both Islam as a religious doctrine and/or Muslims.

Two strong tropes of anti-Muslim hostility identified among grassroots EDL activists in this study - that Muslims seek to 'impose their rules here' and that Muslims 'have no respect' - suggest that one of the key characteristics attributed to the Muslim 'other' is itself the practice of 'othering' (of non-Muslims). Expressions of anti-Muslim sentiment thus include perceptions that the Muslim 'other' constitutes a direct infringement of, or sets itself in superior position to, 
respondents' 'self'. Recognising that 'thoughts and feelings about the Self' are highly implicated in the formation of associations of the 'other' (Ezekiel, 2002: 54) opens the way to questioning the rather one-dimensional vision of the empowered subject of 'othering' found in existing models of Islamophobia.

The most consistent and emotionally charged narrative of 'self identified among respondents in this study is that of 'second-class citizen'. This narrative is rooted in a sense of profound injustice based on the perception, almost universally expressed among respondents, that the needs of others are privileged over their own. While the perceived beneficiaries of that injustice might be racialised (as 'immigrants', 'Muslims' or ethnic minorities), and it is claimed that they are afforded preferential treatment in terms of access to benefits, housing and jobs, the agent responsible for this injustice is understood to be a weak-willed or frightened government that panders to the demands of a minority for fear of being labelled racist. This injustice is understood to be institutionalised through a 'twotier' justice system which privileges minorities whilst discriminating against 'us'.

The narrative of second-class citizenship reveals the way in which sections of the white working class fail to recognise 'self' as privileged majority. They perceive themselves rather as the victims of discrimination and in some cases of violence or abuse; the anger at this is amplified by the conviction that such discrimination and abuse go unrecognised by the media, police and political system when the victims are white. This suggests that even when respondents target anger and 'blame' for their perceived 'second-class' status at government and its agencies rather than immigrant communities, they nonetheless naturalise assumptions of racially based inequality; that 'we' not 'they' should be prioritised is the natural order (Rhodes, 2009).

EDL activism is experienced by respondents in this study as a means of resisting this second-class citizen status. This is accomplished through a discursive reordering of privilege and prejudice and a collective understanding of the EDL as a movement of 'the common people' prepared to 'stand up' and 'fight back' against the government, and wider circles of power controlled by liberal elite 'do-gooders', who have little understanding of the everyday worlds they inhabit.

\section{Emotional and affective dimensions of activism}

The recent rehabilitation of the role of emotions in social movement theory alongside new theoretical impulses from the 'affective turn' in the social sciences, has led to an increasingly nuanced discussion of different types of emotions in movements (Goodwin, Jasper and Polletta, 2001: 20) and how activists perform their networks through diverse bodily movements, techniques and styles, generating distinct emotional tones (Juris, 2008: 89). This shift in the field has largely bypassed studies of extreme and populist radical right movements, however, where collective emotions are seen as consciously orchestrated by leaders among masses in order to construct emotional collectives (Virchow, 2007: 148). This instrumental approach has been questioned by the findings of this study, which suggest that affective bonds within the EDL are generated from the bottom-up 
through a sense of 'togetherness' that emerges from shared activism and that binds members of the movement.

Previous academic studies of the EDL have focused almost exclusively on the ideological dimensions of activism. However, this study found friendship, loyalty and the sense of belonging to a 'family' to be the most frequently cited meanings attached to activism. This is reflected in the repeated claim that EDL members stand up for, and look after, each other and in the practice of mutual care both during and outside of actions. These bonds - experienced as being 'like one big family' - enhance the pleasures associated with activism and thus are central to sustaining it. This confirms Goodwin, Jasper and Polletta's (2001: 20) argument that, while distinct, 'reciprocal' and 'shared' emotions reinforce each other in the formation of a movement's culture. It is important, however, not to romanticise reciprocal emotions and the affective bonds they generate. The sense of collective belonging and emotional support described above is not universal and interpersonal relationships central to the formation and maintenance of the emotional collective can also be a site of tension that ultimately undermines the movement (Jasper, 1998: 419).

While recognising the limitations of the data gathered for a nuanced study of the role of affect in the EDL, an attempt was made in Chapter 7 to capture and analyse moments during activism where affect - understood as non-conscious movement from one experiential state of the body to another - becomes tangible and, sometimes, articulated. These moments included points at which senses are overwhelmed by the crowd, when respondents feel the 'buzz' or 'rush' of the demonstration or are lost in the pleasures of communal singing, chanting and marching. Drawing on Wetherell (2012), it has been suggested here that affect is best understood as a 'practice' rooted in social life and concrete activities rather than as a 'contagion', virtual or transhuman process that takes place outside the subjectivities of those experiencing them (Shields, Park and Davidson, 2011: 318). This approach reconnects emotion, affect and the meanings attached to activism at the cognitive level (Wetherell, 2012: 148).

The entwinement of rationalised and emotional dimensions of activism is epitomised in the understanding of EDL activism by respondents as standing 'loud and proud'. This affective practice - manifest primarily in participation in street demonstrations - is one of a battery of means of 'getting your point across' and 'being heard' in a political system that is perceived to be set up not for dialogue with people but for their compliant listening. EDL activists in this study experience the external political realm as governed by a politics of silencing in which the expression of their views, as well as government policy, are constrained by the application of the 'racism label'. They learn that the best strategy for negotiating this realm is to 'keep your mouth shut'.

This shutting down of political space compounds a wider disengagement with the formal political sphere and a denial of the 'political' by respondents. While such disillusionment with the party political system is increasingly common across the general population, it is striking that, despite their active political engagement, EDL activists in this study often articulated a rejection of politics per 
se, characterising it as meaningless 'debate'. In contrast to the duplicitous chatter of formal politics, activism in the EDL is understood as 'telling it as it is', practised as part of a wider 'non-politics' of action.

This disengagement on the part of EDL activists, it has been argued, is a radical variant of views found in wider society rather than 'a normal pathology unconnected to the mainstream' (Mudde, 2007: 297). This is demonstrated through the absence (with limited exceptions) of alternative anti-democratic ideologies typically associated with traditional far right parties and movements. While activists in this study are highly critical of the contemporary working of democracy, that criticism is directed primarily at governments (past and present) rather than at the democratic system as a whole. The only alternative suggested to parliamentary democracy by respondents (with the exception of the three fringe Infidels activists) was the restoration of the powers of the monarchy.

\section{The politics, and humanity, of research}

This book is political because its original quest for honest enquiry became, in the course of research, a political position. That position might be framed, first, as the recognition that such research is essential, even in fields of study where the need to tackle continued oppression and injustice is evident and urgent. Transgressing the cordon sanitaire erected around movements like the EDL in order to mark out the moral high ground from which the political grievances of others can be safely ignored, dismissed or condemned is to take a political stance. If that transgression is driven not by self-interest (in vicarious living or notoriety) but by the conviction that effective action to combat racism requires honest enquiry (Ezekiel, 1995: $\mathrm{xxxv}$ ), then, it is, notwithstanding its potential to offend, politically progressive.

Second, dismissing individuals participating in movements such as the EDL as blinded by 'fascist' or 'racist' ideology, and thereby excluding them from what constitutes the political, is, in contrast, politically non-progressive. This is because it fails to recognise the impact of wider structural change on white working-class communities (alongside its impact on often even more impoverished ethnic minority communities) (Lone and Silver, 2014: 178) as well as the underlying frustration with the contemporary constitution of politics among those communities. Ashe (2014), considering the collapse of electoral support for the BNP, draws the opposite conclusion. The labelling of the BNP as fascists, Nazis and racists, he argues, is, at least partially effective, since this association of the party is the principal reason voters choose not to vote for the BNP, even if they hold racist points of view themselves. While I would agree with Ashe that an anti-racist ethos and inter-ethnic solidarity are best promoted by sustained, local community-based campaigning and organisations, I am less convinced that 'condemnation strategies' are politically effective in more than particular localised and short-term contexts. The disagreement reflects the insights derived from different observational positions of research. From the viewing point of anti-fascist activism, mainstream political parties appear to 'have pandered to, and legitimised, the politics of the BNP' (Ashe, 2014). In contrast, this study of EDL activists, as well research among 
the kinds of communities from which the movement draws its support (see Lone and Silver, 2014), suggests that the external political environment is experienced as a sphere of condemnation and silencing. From this perspective 'condemnation strategies' are likely to be counterproductive in that they act to consolidate the sense of exclusion and reify resentment. There is widespread agreement that this resentment exists and growing empirical understanding of its contours; the question that continues to divide is how, politically, it should be treated. While Ware (2008: 2) argues that white working-class resentment is used too frequently in current political and media discourse in the UK to explain, and excuse, racist or anti-social attitudes, Kenny (2012: 24) suggests that at least some of the grievances expressed might 'merit a more sympathetic hearing by the state'.

Third, this position is one that views the 'moralisation' of politics as not strengthening but weakening democratic politics. Responding to right-wing populism by labelling it 'extreme-right' and dismissing it through a discourse of moral condemnation is indicative of a wider shift of the political terrain from a struggle between 'right and left' to that between 'right and wrong' (Mouffe, 2005: 4-5), which, for those deemed 'wrong', reinforces the experience of the external political realm as a 'politics of silencing'. This, Mouffe (2005: 71-72) argues, facilitates the potential for right-wing populist movements to exploit popular frustration whilst simultaneously providing people with some form of hope that things could be different; although this is an 'illusory hope', founded on unacceptable mechanisms of xenophobic exclusion, when it is the only channel for the expression of political passions, it is seductive. If 'societies are mechanisms for the distribution of hope' (Hage, 2003: 3, cited in Ware, 2008: 9) it is essential that all are included in the distribution chain.

Finally, this position understands the potential of ethnographic research conducted from the 'other' side of the cordon to get at the humanity of people (Duneier and Back, 2006: 554) and to have political as well as academic significance. Engaging with activists as individuals with real lives allows for the articulation and observation of those lives in all their human dimensions. It provides insight into how and why individuals fail to recognise 'self as the privileged majority, how this contributes to the racialisation of both 'other' and 'self and how this acts to discourage the formation of alliances across ethnic, cultural or religious lines. The sustained presence in the lives of others opens us to capturing those fleeting moments when the oppression of others is recognised and solidarity that cuts across perceived cultural and ethnic differences becomes imminent. To see and hear this requires the researcher to take a stand on the moral low ground, behind the cordon sanitaire, and to practice 'the art of listening' (Back, 2007: 12) in a way that does not silence race but pushes us, often painfully, towards a way of talking about the effects of racialisation that might enable us to move beyond its oppressive force. 